UDC 94(47).084.3

Submitted: 11.01 .2016

LBC (T)63.3.(0).6

Accepted: 14.03 .2016

\title{
THE ROLE OF AVIATION IN THE MALGOBEK DEFENSIVE OPERATIONS (SEPTEMBER-OCTOBER 1942)
}

\author{
Timur Kh. Matiev \\ Ingush State University, Magas, Russian Federation
}

\begin{abstract}
The article presents the main characteristics of the factors and the results of the use of air forces of Germany and the Soviet Union during the military operations in September-October 1942, during the Malgobek defensive operation. The operation was one of the most important components of the battle for the Caucasus and throughout the summer and autumn campaign on the Eastern Front of World War II. It was attended by the main forces opposing each other in the Caucasus of the Soviet and German troops. Both sides here have thrown considerable force aircraft. On the Soviet side it was the 4th Air Army, while the German part consisted of the forces of the 4th Air Fleet.

At the same time dispersion of forces into two directions - Caucasian and Stalingrad in summer of 1942 did not allow the German command to set air superiority. On the other hand, the Soviet Union failed to achieve the excellence as well.

Despite this the whole Soviet aircraft operated in this situation more effectively and had a tangible advantage. This result was achieved due to the concentration of a significant number of aircraft, as well as improvement of the quality of parts of the Air Force aircrew, operating in the Caucasus. The main types of action on both sides were hitting attack and bomber aircraft on airfields, troop concentrations, crossings; direct support of ground troops, as well as the struggle for the conquest of the air, which was conducted mainly by the fighter aircraft.

Control over the situation on the battlefield, which the Red Army Air Force maintained that throughout the Malgobek operations played an important role in achieving the ultimate success of the defensive measures of the Soviet command in this battle.

Key words: aviation, 4th Air Army, the Luftwaffe, 52 Squadron, Transcaucasian front, plaque, fighters, bombers.

УДК 94(47).084.3

ББК (Т)63.3.(0).6

Дата поступления статьи: 11.01.2016

Дата принятия статьи: 14.03.2016
\end{abstract}

\section{РОЛЬ АВИАЦИИ В МАЛГОБЕКСКОЙ ОБОРОНИТЕЛЬНОЙ ОПЕРАЦИИ (СЕНТЯБРЬ - ОКТЯБРЬ 1942 г.)}

\author{
Тимур Хусенович Матиев \\ Ингушский государственный университет, г. Магас, Российская Федерация
}

\begin{abstract}
Аннотация. В статье излагаются основные характерные особенности, факторы и итоги использования военно-воздушных сил Германии и СССР в ходе военных операций сентября - октября 1942 г. в ходе Малгобекской оборонительной операции. Данная операция явилась одной из важнейших составных частей битвы за Кавказ и всей летне-осенней кампании на советско-германском фронте Второй мировой войны. В ней участвовали главные силы противостоящих друг другу на кавказском направлении советских и германских войск. Обе стороны бросили сюда значительные силы авиации. С советской стороны это была 4-я воздушная армия, с немецкой - часть сил 4-го воздушного флота.

В то же время распыление сил на два направления - кавказское и сталинградское - летом 1942 г. не позволило германскому командованию создать на данном участке превосходства в воздухе. С другой стороны, не удалось добиться безусловного превосходства и Советскому Союзу.

Несмотря на это, в целом советская авиация действовала в данной ситуации более успешно и обладала ощутимым преимуществом. Этого результата удалось добиться за счет концентрации значительного количества самолетов, а также повышения качества летного состава частей ВВС, действовавших на кавказском направ-
\end{abstract}


лении. Основными видами действий обеих сторон были удары штурмовой и бомбардировочной авиации по аэродромам, скоплениям войск, переправам; непосредственная поддержка наземных войск, а также борьба за завоевание господства в воздухе, которая велась силами в основном истребительной авиации.

Контроль над ситуацией над полем боя, который в целом сохраняли ВВС Красной армии на всем протяжении Малгобекской операции, сыграл важную роль в достижении конечного успеха оборонительных мер советского командования в данном сражении.

Ключевые слова: авиация, 4-я воздушная армия, люфтваффе, 52-я эскадра, Закавказский фронт, налет, истребители, бомбардировщики.

Контроль за ситуацией в воздухе приобрел особое значение в военных операциях осени 1942 г. на Северном Кавказе [17, с. 323]. Южный участок советско-германского фронта, выбранный вермахтом в качестве направления главного удара кампании 1942 г., сразу привлек главные силы сторон, в том числе и воздушные. Воздушные силы обоих противников на Северном Кавказе в целом были примерно равны: германский 4-й воздушный флот генерал-полковника В. фон Рихтгофена насчитывал около 600 самолетов, а противостоявшие ему 4-я, 5-я советские воздушные армии и авиация Черноморского флота - от 640 до 460 самолетов [9, с. 30].

Непосредственно в районе Малгобека с немецкой стороны действия наземных войск поддерживала лишь часть сил 4-го воздушного флота, а войска Красной Армии прикрывали силы 4-й воздушной армии генерала К.А. Вершинина. (Кроме того, защищавшая подступы к Малгобеку 9-я армия имела в своем составе 750-й смешанный авиаполк, a ее соседи: 37-я армия - 446-й смешанный авиаполк, а 46-я армия - 863-й, 927-й, 975-й истребительные авиаполки) [4].

4-я воздушная армия была сформирована 22 мая 1942 г. на основании приказа НКО CССР от 7 мая 1942 г. на базе управления и соединений ВВС Южного фронта в составе 216-й, 217-й и 229-й истребительных, 230-й штурмовой, 218-й ночной бомбардировочной и 219-й бомбардировочной авиадивизий, 7 отдельных смешанных авиаполков [14, с. 388]. 29 июля армия была включена в состав Северо-Кавказского фронта, 14 августа переподчинена командующему войсками Закавказского фронта 2-го формирования. Возглавил ее генерал-майор авиации, впоследствии Главный маршал авиации Константин Андреевич Вершинин (с 8 сентября его сменил генералмайор Н.Ф. Науменко) [6, с. 84].
11 августа 1942 г. 216-я авиадивизия в полном составе перебазировалась за реку Терек на аэродром Тулатово. 12 августа в ее состав на этом аэродроме вошел 84-й «а» истребительный авиаполк майора Антонова с 21 самолетом И-153 «чайка». Эта машина к осени 1942 г. во всех отношениях устарела, и летчики не любили ее главным образом за небольшую скорость. Но было у нее и достоинство - высокая маневренность. «Чайка» свободно облетала горы, забиралась в ущелья.

Вскоре в авиасоединения поступило распоряжение командарма 4-й воздушной армии Вершинина: максимально использовать «Чайки» для штурмовки и бомбежки вражеских войск в горах. Появились и асы этого дела. На тихоходных, но юрких «Чайках» они находили и штурмовали противника в таких местах, которые для других самолетов вообще были недоступны [11, с. 116].

88-й истребительный авиаполк вначале базировался на аэродроме Орджоникидзевская, 103-й штурмовой и 45-й истребительный полки - на аэродроме Нестеровская. Однако с 13 августа дислокация снова изменилась. Штаб дивизии, 88-й и 84-й «а» истребительные полки обосновались в Тулатово, 103-й штурмовой и 45-й истребительный полки обживали аэродром Орджоникидзевская [7, c. 415].

С 17 августа 4-я воздушная армия сосредоточивала свои основные силы севернее Моздока.

В течение всей второй половины августа наша авиация продолжала наносить удары по войскам противника, пытавшегося на различных участках форсировать Терек. Маневрируя своими главными силами, авиация быстро сосредоточивалась там, где создавалось наиболее тяжелое положение.

Стремясь прикрыть свои войска от ударов с воздуха, заметно активизировалась вра- 


\section{ОТЕЧЕСТВЕННАЯ ИСТОРИЯ}

жеская истребительная авиация. Однако наши летчики крепко удерживали инициативу за собой и из каждого воздушного боя выходили победителями. Примером тому может служить схватка 17 августа одиннадцати Як-1 и семи ЛаГГ-3 из 217-й истребительной авиадивизии с девяткой Ме-109ф и шестеркой Хе-113. В итоге было уничтожено шесть вражеских машин и шесть подбито. Наши самолеты вернулись без потерь.

Как мы видим, вражеская авиация не добилась абсолютного господства в воздухе. Советские пилоты сражались достаточно уверенно, смело, инициативно и во многих случаях добивались победы.

В то же время и советская авиация испытывает под Малгобеком острую нехватку боевых машин, особенно штурмовой и бомбардировочной авиации. Характерно участие в бомбово-штурмовых налетах на аэродромы противника групп, составленных исключительно из истребителей, в лучшем случае разбавленных истребителями-бомбардировщиками. Это как раз и указывает на недостаток бомбардировочной и штурмовой авиации, гораздо лучше приспособленной для проведения таких действий. Вероятно, при организации полноценной атаки с участием ударной группы, сформированной из специально приспособленных для бомбово-штурмовых действий самолетов, с мощным истребительным прикрытием, результаты налетов могли бы стать более впечатляющими.

При этом немецкие источники указывают на активность советской авиации уже в предшествующие недели, в период боев за Моздок. В. Тике отмечает: «Необычная активность советской авиации создавала помехи выдвижению немецких соединений. Советские самолеты различных типов, в том числе английского и американского производства, кружились над районами сосредоточения и демонстрировали подавляюще превосходство» $[13$, с. 152]

Немецкие ВВС участвовали в Малгобекской операции не в лучшем состоянии. На недостаточность воздушной поддержки наземных войск в ходе боев за Малгобек наперебой свидетельствуют немецкие источники. В частности, Т. Хоффман в истории 5-й танковой дивизии СС, говоря о событиях тех дней, пишет: «Одновременными сражениями на Волге и на Кавказе была охвачена группа армий “Юг”, явно ослабленная. Особенно это касалось действий воздушного флота, основная задача которого заключалась в поддержке и обеспечении армии, воюющей в Сталинграде» $[15$, с. 12].

В. Тике, непосредственный участник боев на Тереке, пишет: «Как раз во время боев на Тереке простые солдаты в окопах частенько нелестным словом поминали люфтваффе. Господство советской авиации в воздухе было подавляющим. Немецкие истребители лишь время от времени появлялись в воздухе, зачастую тогда, когда советские истребители уже улетели» [13, с. 152].

Даже в наиболее напряженные моменты боев севернее Малгобека, когда советские войска предприняли попытку контрудара и немецкие наземные части остро нуждались в поддержке с воздуха, люфтваффе действовали на малгобекском направлении в основном небольшими группами. Так, в сводке боевых действий 9-й армии Северной группы войск Закавказского фронта за 9 сентября говорится: «Авиация противника в 14:15 9 сентября 6 самолетами бомбила наши боевые порядки юго-западнее отметки 154» [16, л. 35].

Немецкому командованию в условиях острого дефицита не только авиационной техники, но и поредения кадрового состава люфтваффе, перед лицом необходимости решения сразу нескольких задач оставалось сделать ставку на профессионализм и высокий уровень подготовки своих пилотов. Другими словами, было принято решение рискнуть, поставив на качество в противовес количеству. Поддержку наземных войск на малгобекском направлении должна была осуществлять прославленная Jagdgeschwader 52 (JG 52) - 52-я истребительная эскадра, соединение, которое действительно было едва ли не самым заслуженным в люфтваффе. Достаточно сказать, что в составе эскадры служили три лучших аса Германии, одновременно считающиеся лучшими истребителями в истории мировой авиации - Гюнтер Ралль, на счету которого официально числится 275 побед, Герхард Баркхорн с 301 победой и, наконец, самый результативный летчик Второй мировой войны Эрих Хартманн, на счету которого, опять же 
по немецкой статистике, оспариваемой некоторыми исследователями, числятся 352 воздушные победы [5, с. 399]. Вооружена эскадра была представлена исключительно истребителями «мессершмитт» Bf-109.

По штату в немецкой авиагруппе насчитывалось 30 самолетов, однако в Армавире 3-я группа JG-52 (по немецкой номенклатуре III/52) едва насчитывала половину исправных самолетов. Уже в начале сентября на данном участке фронта основную ударную силу составляли только около дюжины Ме-110 из ZG1 «Wespen» и Ме-109 третей группы JG52. В. Тике приводит слова из письма к нему майора Голлоба, написанного уже после войны: «Во время боев на Тереке исправным было едва ли больше одного звена из четырех машин. Поэтому на задание мы вылетали обычно парой, то есть по два. Самолетов не было, бензина не было. Боеприпасов не хватало. Приходилось выходить из положения за счет тактического превосходства, чтобы, действуя мелкими подразделениями, как можно лучше прикрывать линию фронта с воздуха» [13, с. 171].

Трудно судить, насколько искренен в своих воспоминаниях бывший и. о. командира JG-52. Если принять на веру его слова, то немцы были вообще не в состоянии хоть какнибудь прикрыть наземные войска и бороться с советской авиацией. Между тем и документы советских штабов, и оперативные сводки, да и воспоминания очевидцев и участников событий с советской стороны - как воевавших в наземных войсках, так и военных летчиков - говорят о довольно высокой активности люфтваффе. В воспоминаниях советских летчиков - участников боев над Тереком в августе - октябре 1942 г. также нередко можно встретить упоминания о численном превосходстве атаковавших их немецких самолетов. Если и не на протяжении всей битвы, то в отдельные ее дни упоминаются воздушные бои с участием куда как большего числа немецких самолетов, чем упоминаемые Голлобом «четыре машины».

При этом следует помнить, что не только истребители 52-й эскадры составляли немецкие воздушные силы в ходе боев за Малгобек. К действиям по прикрытию наземных войск и их поддержке привлекались и другие соединения люфтваффе. В частности, это были и двух- моторные истребители Мe-110 («Zerstorer») из 1-й группы 1-й эскадры двухмоторных истребителей, базировавшейся на аэродроме в Краснодаре, а также пикирующие бомбардировщики Ю-87 «Stuka» 77-й эскадры, базировавшейся на аэродромах в Солдатской (3-я группа) и Белореченской (в составе штабной эскадрильи, размещавшейся здесь, также летали и Ме-110) [13, с. 171].

Ситуация, в которой обе стороны наперебой утверждают об острой нехватке самолетов и трудностях со снабжением, в то же время утверждая, что у противника с этим дела обстояли хорошо, ставит всякого исследователя, не имеющего полного доступа ко всем архивам обеих сторон, в весьма затруднительное положение. Тем не менее даже те архивные документы обеих сторон, которые имеются в нашем распоряжении, в совокупности с мемуарами очевидцев и участников событий, позволяют утверждать, что крайние утверждения как всегда являются либо преуменьшением, либо преувеличением. Для создания подавляющего превосходства или вообще постоянного превосходства как такового у немцев над Малгобеком сил и вправду было недостаточно. В то же время аргументированно говорить о «четырех самолетах», которыми якобы ограничивалась поддержка наземных войск вермахта под Малгобеком, вряд ли возможно.

Активные и результативные действия советской авиации на малгобекском направлении отмечаются и в документах. Так, в уже цитировавшейся оперсводке 9-й армии от 9 сентября указывается: «Наша авиация в течение дня производила штурмовку и бомбометание живой силы и техники противника в районе Терская, Кизляр. В 6:00 бомбардировкой аэродрома противника.... уничтожено 7 caмолетов» [16, л. 37].

А командир 11-го гвардейского корпуса генерал И.П. Рослый так оценивает в своих мемуарах действия летчиков: «Вовсю поработали и летчики 4-й воздушной армии. Только за один день 13 сентября они совершили 430 боевых вылетов. Действуя на высоте 100150 метров, наши Ил-2 расстреливали живую силу неприятеля, поджигали его танки» [12, с. 119]. Помимо бомбового вооружения, штурмовики Ил-2 часто использовали реактивные 
снаряды (как указывалось в донесениях из немецких частей, подвергшихся этим ударам, «похожие на те, которые применяют “сталинские органы"») [18, f. 826].

Как указывает в своей работе А.А. Гречко, «умелый и своевременный маневр действиями основных сил авиации на наиболее угрожаемые направления, нанесение ударов более крупными группами (10-20) самолетов способствовало успешному выполнению задач» [3, c. 108].

При этом не обходилось и без ошибочных ударов по собственным войскам - того, что в современной военной практике называется «дружественным огнем». Так, в 17.00 10 сентября 1942 г. район исходных позиций 52-й танковой бригады, которая четвертый день вела напряженные бои с атакующими танками и пехотой противника, подвергся налету собственной авиации. В результате бомбежки и обстрела были подбиты две машины «Додж». Кроме того, один человек был убит и 5 человек ранено.

Несвободны были от подобного «дружественного огня» и немцы. Так, 5 сентября 1942 г. командир 3-й группы 52-й эскадры майор фон Бонин обратился с официальным документом в штаб 52-го армейского корпуca, в котором жаловался на трудности, чинимые огнем собственной зенитной артиллерии действиям его истребителей по прикрытию наземных войск и переправ. Указывалось на факты повреждений, вынужденных выходов из боя и аварийных посадок, связанных с огнем своих же зениток. Фон Бонин требовал принятия срочных мер и передачи приказа зенитным частя не открывать огонь во время атаки своими истребителями вражеских бомбардировщиков. В противном случае командир III/52 грозился отдать приказ своим летчикам не залетать при отражении налетов противника в зону действия своей наземной ПВО, что резко ограничивало эффективность действий истребителей $[18$, f. 20$]$.

Советские бомбардировщики 219-ой БАД подполковника Батыгина Пе-2 и «Бостоны» (или как их еще называли в 4-ой Воздушной армии, Б-3) доставляли много хлопот немецким наземным войскам. Но, летая почти без сопровождения, советские бомбардировщики и сами несли серьезные потери. Как отмечал наблюдатель из 4-ой Воздушной армии, который находился в дивизии: «6 сентября 1942 года, в 13:51, шесть Б-3 в сопровождении 8 ЛаГГ-3 бомбили переправу. Один бомбардировщик был поврежден зенитным огнем и при возвращении был атакован истребителями противника, экипаж покинул самолет». Ближе к вечеру был сбит еще один «Бостон». На следующий день обстановка развивалась по тому же сценарию. Именно над переправами советские авиаторы в тот период несли и наибольшие потери. 2 сентября 1942 г. в немецких сводках значатся 6 сбитых самолетов [18, f. 111], 14 сентября - 3 самолета [18, f. 367].

Накал борьбы, которая происходила в небе над переправами через Терек, особенно в первой половине сентября - на начальном этапе Малгобекской операции - не уступали кипевшему в тот момент противоборству советских и немецких войск на земле [2, с. 92]. Активность советских летчиков над временными мостами через Терек была столь велика, что саперы противника едва успевали восстанавливать разрушаемые бомбовыми ударами переправы.

Это вынуждало немецких штабистов в своих документах уделять целые станицы описанию ярости вражеских воздушных ударов и урона, наносимого ими наземным войскам, а командование противника - стягивать все новые и новые зенитные средства для прикрытия наземных войск, попутно бросая на противодействие советским налетам свои немногочисленные истребительные части. Например, в ходе налета в ночь на 5 сентября, продолжавшегося с перерывами свыше 8 часов, в районе переправ были повреждены почти все находившиеся там транспортные средства, бомбами были поражены также два зенитных орудия [18, f. 24]. Сообщается о разрушении мостов, частичном затоплении понтонов $[18, \mathrm{f} .25]$. Согласно немецким сводкам, налеты на мосты в Моздоке шли почти непрерывно с 18 часов 4 сентября до 3.30 утра 5 сентября. Отдельные немецкие документы говорят о 80-100 самолетах (по выводам немцев, главным образом бомбардировщиков «Бостон-Дуглас» американского производства), участвовавших в налетах, хотя эта цифра представляется все же завышенной. Со- 
общается о 400-1 000 бомбах, сброшенных с высоты 3 000-3 500 м на мосты и переправы в Моздоке, а также о скоплениях войск в предмостных районах [18, f. 24]. Дневная сводка штаба 52-го армейского корпуса отмечает «отличное качество пилотного материала» советской бомбардировочной авиации (то есть высокий уровень мастерства советских летчиков) [18, f. 25].

Большой вклад в оказание помощи наземным войскам и достижение победы в воздухе в ходе Малгобекской операции внесли женщины-летчицы легендарного 588-го ночного бомбардировочного авиаполка (впоследствии - 46-й гвардейский бомбардировочный полк) под командованием майора Е.Д. Бершанской, сражавшегося в это время в составе 4-й воздушной армии. Под аэродром летчицы приспособили небольшую площадку перед огромным колхозным садом на берегу Ассы, в окрестностях Ассиновской, в котором привольно разместились маленькие самолеты ночного бомбардировочного полка. Летчицы проявляли не меньшую изобретательность, чем прославленные асы дневной авиации. Для большей эффективности они начали практиковать полет парами. Первый самолет подходил к цели, отвлекая на себя огонь, а второй экипаж в это время спокойно и без помех бил по основному объекту. Первый же сбрасывал бомбы на прожекторные и зенитные установки.

Однако не всегда можно было лететь парой. Тогда летчицы Бершанской прибегали к такой хитрости. Подходя к цели на гораздо большей высоте, чем нужно для бомбометания, они убирали газ, и самолет бесшумно планировал, так же бесшумно уходя от цели. Только отойдя на более или менее безопасное расстояние, прибавлялись обороты мотору. Этот тактический прием очень полюбился всему летному составу и справедливо считался одним из самых надежных и эффективных.

В ходе вылетов летчицы постоянно уделяли внимание и техническому усовершенствованию своей боевой работы. Инженер по оборудованию Илюшина предложила поставить на какой-нибудь самолет рацию, чтобы сведения о погоде получать прямо из района цели.

График боевой работы у женского авиаполка был очень напряженным. Днем самоле- ты и экипажи находились на аэродроме в Слепцовской, на площадках в Самашках и Нестеровской $[19$, f. 906]. Боевая работа начиналась ночью и продолжалась до утра. За ночь летчицы совершали 6-8 вылетов [1, с. 119].

Это было обусловлено малой бомбовой нагрузкой, которую за один вылет мог взять с собой самолет У-2 или Р-5 - основные типы машин, на которых сражались девушки из полка Бершанской. Летчицы брали в вылет до 200 кг бомбовой нагрузки (две 100-килограммовые или четыре 50-килограммовые бомбы, а также некоторое количество зажигательных бомб). Самолеты ночного бомбардировочного авиаполка уходили на задание по одному, с интервалом в 3-4 минуты непрерывно бомбили с высоты в 800-1000 м обнаруженные цели [10].

Бывали случаи, когда самолеты По-2 работали как корректировщики, непосредственно содействуя артиллеристам [8, с. 115].

Советская авиация весьма активно действовала на всем протяжении сражения за Малгобек, что подтверждается как документами, так и воспоминаниями очевидцев и участников событий как с советской, так и германской стороны. Когда противник, подтянув резервы, овладел Малгобеком и Нижним Курпом и продолжал сосредоточивать силы для прорыва в направлении Грозного и Владикавказа, советские летчики днем и ночью уничтожали переправы через Терек и Курп, наносили удары по скоплениям гитлеровцев. Только за 13 сентября было произведено 430 самолетовылетов, из них 150 - ночью. В результате враг потерял 20 танков, до 100 автомашин, несколько бензоцистерн и около батальона пехоты. Во время ночного бомбометания в Малгобеке отмечено 13 пожаров и 5 взрывов, в лесу южнее Павлодольской и у переправы - 13 пожаров и 15 взрывов. За пять месяцев воздушных боев только истребители ВВС Закавказского фронта произвели 2809 вылетов [6, с. 88]. Только истребителями в ходе Малгобекской оборонительной операции было сбито 115 самолетов противника [2, с. 115].

Именно возросшее мастерство и активность советских летчиков в сочетании с трудностями, испытываемыми немцами в поддержании необходимой численности своих авиационных частей на Северном Кавказе, созда- 
ли в небе над Малгобеком ситуацию, еще год и даже полгода назад непредставимую для войны в воздухе на советско-германском фронте. Они не позволяли и не позволили в итоге противнику сколько-нибудь эффективно наладить взаимодействие своих наземных сил и авиации на протяжении всего сражения. Таким образом, можно уверенно говорить о том, что советской авиации в ходе Малгобекской оборонительной операции удалось выиграть битву в воздухе, что во многом определило успех действий наземных сил в обороне.

\section{СПИСОК ЛИТЕРАТУРЫ}

1. Аронова, Р. Е. Ночные ведьмы / Р. Е. Аронова. - М. : Советская Россия, 1969. - 288 с.

2. Битва за Кавказ. - М. ; Владикавказ : Триада-ф, 2002.-411 c.

3. Гречко, А. А. Битва за Кавказ /А. А. Гречко. - М. : Воениздат, 1969. - $496 \mathrm{c}$.

4. Закавказский фронт. Боевые действия Красной Армии в Великой Отечественной войне. - Электрон. текстовые дан. - Режим доступа: http://bdsa.ru/ index.php?option $=$ com_content\&task $=$ view\&id $=$ 881\&Itemid=28. - Загл. с экрана.

5. Залесский, К. А. Вожди и военачальники Третьегорейха / К. А. Залесский. - М. : Вече, 2000.-576 с.

6. Исаев, В. В. За чистое небо / В. В. Исаев. Харьков : Прапор, 1975. - 240 с.

7. Карпович, В. П. На «Ишаках» и «Мигах»! / В. П. Карпович. - М. : Яуза, 2007. - 445 с.

8. Магид, А. С. Гвардейский Таманский авиационный полк / А. С. Магид. - М. : Изд-во ДОСААФ, 1960.-288 c.

9. Мощанский, И. Б. Оборона Кавказа. Великое отступление 25 июля - 31 декабря 1942 г. / И. Б. Мощанский. - М. : Вече, 2010. - 192 c.

10. Пляц, А. Город на Терском хребте // Сердало. $-2007 .-8$ дек. (№ 160).

11. Полководцы и военачальники Великой Отечественной. - М. : Молодая гвардия, 1985. Вып.3. -187 с.

12. Рослый, И. П. Последний привал - в Берлине / И. П. Рослый. - М. : Воениздат, 1983.- 303 с.

13. Тике, В. Марш на Кавказ. Битва за нефть / В. Тике. - М. : Эксмо, 2005. - 448 с.

14. Феськов, В. И. Красная Армия в победах и поражениях 1941-1945 гг. / В. И. Феськов, К. А. Калашников, В. И. Голиков. - Томск : Изд-во ТГУ, 2004. $-631 \mathrm{c}$.

15. Хоффман, Т. Дивизия СС «Викинг». Гитлеровский интернационал / Т. Хоффман. - М. : Эксмо, 2009. - 448 c.
16. Центральный архив Министерства обороны РФ. - Ф. 464. - Оп. 5689. - Д. 89.

17. Януш, С. В. Битва за Кавказ: проблемы войсковых операций (1942-1943 гг.) : дис. ... д-ра ист. наук / Януш Сергей Владимирович. - Ставрополь, 2006. $-642 \mathrm{c}$.

18. U.S. National Archives and Records Administration (далее-NARA). - T-314. - R. 1290.

19. NARA.-T-315. - R. 1267.

\section{REFERENCES}

1. Aronova R.E Nochnye vedmy [Night Witches]. Moscow, Sovetskaya Rossiya Publ., 1969. $288 \mathrm{p}$.

2. Bitva za Kavkaz (1942-1943 gg.) [Battle for the Caucasus (1942-1943)]. Moscow; Vladikavkaz, Triada-f Publ., 2002. $411 \mathrm{p}$.

3. Grechko A.A. Bitva za Kavkaz [Battle for the Caucasus]. Moscow, Voenizdat Publ., 1969. 496 p.

4. Zakavkazskiy front. Boevye deystviya Krasnoy Armii $v$ Velikoy Otechestvennoy voyne [Transcaucasian Front. Fighting the Red Army in the Great Patriotic War]. Available at: http://bdsa.ru/ index.php?option $=$ com content\&task $=$ view\&id $=$ 881\&Itemid $=2$.

5. Zalesskiy K.A. Vozhdi $i$ voenachalniki Tretyego reykha [Leaders and Military Commanders of the Third Reich]. Moscow, Veche Publ., 2000. 576 p.

6. Isaev V.V. Za chistoye nebo [For Clear Sky]. Kharkiv, Prapor Publ, 1975.240 p.

7. Karpovich V.P. Na "Ishakakh" $i$ "Migakh" [On the "Ishacks" and "MiGs"!] Moscow, Yauza Publ., $2007.445 \mathrm{p}$.

8. Magid A. Gvardeyskiy Tamanskiy aviatsionnyy polk [Taman Guards Aviation Regiment]. Moscow, DOSAAF Publ., 1960. 288 p.

9. Moshchanskiy I.B. Oborona Kavkaza. Velikoe otstuplenie 25 iyulya-31 dekabrya $1942 \mathrm{~g}$. [The Defense of the Caucasus. Great Retreat of July 25 - December 31, 1942]. Moscow, Veche Publ., 2010. 192 p.

10. Plyats A. Gorod na Terskom khrebte [City on Terek Ridge]. Serdalo, 2007, no. 160.

11. Polkovodtsy $i$ voenachalniki Velikoy Otechestvennoy voyny [The Military Commanders of Great Patriotic War]. Moscow, Molodaya gvardiya Publ., 1985, iss. 3.187 p.

12. Roslyy I.P. Posledniy prival v Berline [Shady Rest in Berlin]. Moscow, Voenizdat Publ., 1983. 303 p.

13. Tike B. Marsh na Kavkaz. Bitva za neft [Marsh to the Caucasus. The Battle for Oil]. Moscow, Exmo Publ, 2005. $448 \mathrm{p}$.

14. Feskov V.I. Kalashnikov A.S., Golikov V.I. Krasnaya Armiya v pobedakh i porazheniyakh 1941- 
$1945 \mathrm{gg}$. [The Red Army in the Victories and Defeats of 1941-1945]. Tomsk, Izd-vo TGU, 2004. 631 p.

15. Hoffman T. Diviziya SS “Viking”. Gitlerovskiy internatsional [SS Division "Viking”. Hitler International]. Moscow, Exmo Publ., 2009. 448 p.

16. Tsentralnyy Arkhiv Ministerstva oborony RF [The Central Archive of the Ministry of Defence of the Russian Federation], F. 464, Op. 5689, D. 89.
17. Yanush S.V. Bitva za Kavkaz: problemy voyskovykh operatsiy (1942-1943): dis. ... d-ra ist. nauk [Battle for the Caucasus: Problems of Military Operations (1942-1943). Dr. hist. sci. diss.]. Stavropol, 2006. 642 p.

18. U.S. National Archives and Records Administration, T-314, R. 1290.

19. U.S. National Archives and Records Administration, T-315, R. 1267.

\section{Information About the Author}

Timur Kh. Matiev, Candidate of Sciences (History), Associate Professor, Acting Head of Department of History, Ingush State University, Prosp. Zyazikova, 7, 386001 Magas, Russian Federation, tmt_77@list.ru.

\section{Информация об авторе}

Тимур Хусенович Матиев, кандидат исторических наук, доцент, и. о. заведующего кафедрой истории, Ингушский государственный университет, просп. Зязикова, 7, 386001 г. Магас, Российская Федерация, tmt_77@list.ru. 